\title{
The Role Of Communication In Women's Status: A Case Study Of UNESCO Activities
}

\author{
Abida Perveen \\ Sheikh Zayed Islamic Research Centre \\ University of Karachi
}

\begin{abstract}
This article reviews the activities and research of UNESCO related to mass media and its role enhancing the status of women in the women's decade. The role of communication in changing the status of women is important because of its influence on our daily routine, behaviour, attitude, life styles and choices. It also highlight the initial researches conducted by UNESCO to evaluate the change in the images of women after women decade.

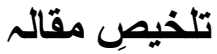

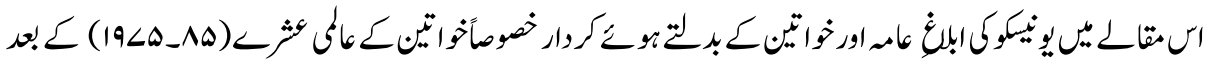

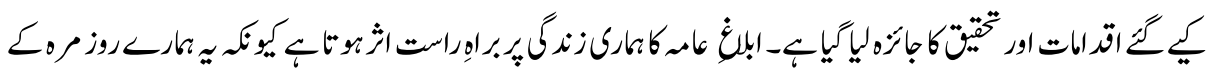

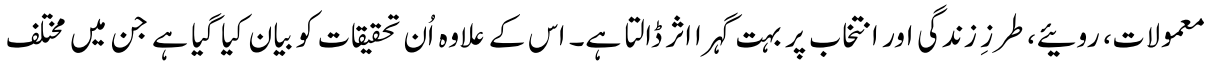

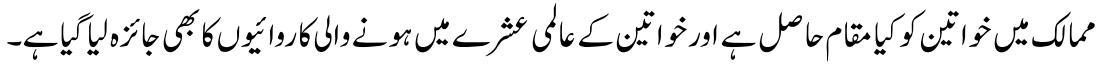

\section{Introduction}

The world plan of action adopted at the world conference for International Women's year, Mexico City in 1975, stressed the special importance of mass media in enhancing the status of women. However, over the next two decades, the United Nations prepared a more coordinated programme for the development of women through full use of mass media (World Conference of UN Decade for Women, 1980). It concluded that equality, development and peace for women should be the objectives of the UN (1975-1980), and in attaining these objectives "a more detailed and more coordinated programme of action in Communication field" reflects the importance of the relationship between women's status and the role of information and Communication". It highlights women's lack of control over or even simple access to communication channels as both a symptom and a cause of their disadvantaged position and proposed a series of specific action for change (World Conference of UN Decade for Women, 1980). This article explores the role of communication in the changing the status of women. 


\section{Background}

To review the status of women in different countries, the UN circulated a questionnaire and sponsored or co-sponsored at least 12 regional and international meetings, and the theme was women and communication.

The review of the activities during the first half of the decade concluded that the lessons for the future to be drawn from this review are many. First, it proved that any measures for women isolated from the major priorities, strategies and sectors of development cannot result in any substantial improvement in attaining the goals of the Decade. Second, legislative and developmental action, unless they are accompanied by positive and concerted action to change attitudes and prejudices cannot be fully effective. Third, mere provision of equal rights, development services and opportunities will not, by themselves, help women to avail of them, without simultaneous special supportive measures, e.g. legal aid, earmarking of benefits, information and knowledge, institutional innovation etc.

Transnational communication and advertising, new information and communication technologies, planning and development of communication infrastructures, democratization of communication, professional practices of communicators - these themes do not figure in either the national or the international measures proposed in the programme of Action. Consequently, the proposals lack the strength which could have come from a more articulated cohesion with the developmental sector to which they related.

At the same time, there is no doubt that priorities and strategies debated or implemented in the communication sector itself have - at both national and international levels -failed miserably to acknowledge the existence of women as a constituent group, with its own complex profile, exigencies and rights. For example, neither the MacBride Report nor the International Programme for the Development of Communication (IPDC) - the two major substantive outcomes of the international debate of the 1970s on information and communication - place any particular emphasis on women's needs, although they are both part of an international response to the very issues which women themselves highlight as problematic in their relationship to the communication media: access, control, training needs, under-representation, marginalization, distortion. The MacBride Report devotes 2 of its 250 substantive pages, and 1 of its 82 recommendations, to women's communication rights and needs. A truly serious analysis of these might have led to some detailed discussion of women in the contexts of, for example, transnationalization, of advertising, of the formation of public opinion, of infrastructures, of professional communicators. Instead, the issue of women is collapsed into two pages 
on 'equal rights for women', which sit somewhat uneasily in a chapter entitled 'Images of the World' (World Conference of the UN Decade for women, 1980).

The IPDC was set up in 1981 with the practical aim of developing possibilities for indigenous communication, through the provision of equipment, training and the building up of basic infrastructures. Three quarters of the requests for assistance which it receives include training activities. Yet, during its first four years, the IPDC did not fund a single project in which women were the principal beneficiaries.

\section{Communication}

From birth to death communication plays an important part in women's lives. Whatever women's occupations or leisure time activities, communication has a role. In fact, if people were asked to analyze how they spend most of their working day, the prime responses would be "Communicating or "being communicated to". In reality, communication is "the essential human connection" (Montagu and Matson, 1979). Whether in pictures or music, verbal or no-verbal, frightening or amusing, clear or unclear, purposeful or accidental, informative or persuasive, person to person or mediated, communication is women's link to the rest of humanity. It provides everything human beings do.

As an individual, human being are influenced by the media. Perhaps you can even programme your day by then. You may rise to the sound of music or news on the radio, dress while watching the fashion show. Morning News feat breakfast while perusing the morning paper, travel to work while listening to favourite radio stations or tapes, eat dinner while listening to or watching the evening news, fill the evening hours and unwind by watching television or going to movie, and finally fall asleep to television, stereo or radio. The media that provide fabric of an era also influence and affect the values, attitudes, and lifestyles of the people born into that era. With media technology, there is no going backward. Thus, it makes sense for human beings to reflect or set their priorities, how they amplify perceptions and how they shape or modify human consciousness (Mac Bride, 1980).

Mass media teaches and guides women in establishing, extending, or displacing meaning, lead them in approving or disapproving portrayals, and encourage to reinforce or replace their system of values.

The themes like communication, information and communication technologies, planning and development of communication infrastructures, and democratization of communication are proposal arenas in the programme action. The priorities and strategies debated in the communication sector itself have at both national and international levels 
failed to acknowledge the existence of women as a constituent group' with its own complex profile, ex-agencies and rights. At international level the women's needs are problematic in their relationship to the communication media.

The communication development over the last decade, two set of discussions - one emanating from focusing on the needs of women, the other arising from and related to mainstream communication problems have been carried out and have voiced parallel concerns. To achieve lasting change in the women and communication relationship, the ultimate aim must be convergence at the interests.

UNESCO's activities in the field of women and communication started in 1975. It has included reinforcing lines of direction. The First World Conference at International Women's Year was held in Mexico in 1975. Earlier a UNESCO Pilot Project in Senegal continued for five years. In this project, professional training courses in television techniques for both men and women were given. It stressed the use of television for the social education of women throughout world. The plan of action adopted by the World Conference acted as a world-wide catalyst, leading to increase in women's activities in the media. The plan recognized the potential of media in promoting social and attitudinal changes in developing women's participation in various societies. It particularly emphasized that women should be employed in greater number in decision -making, professional and creative capacities within media organization (Medium Term Plan, UNESCO, 1977).

In order to establish a favour for the exchange of experiences in community -based population growth control, the Asia Center for Population and Community Development was set up in 1978 with a view to transferring elements and determining its suitability in different context. At the same time, it was recognized that the extent to which the project can be replicated will be partly limited by its very nature, the essence of which is responsiveness to local sensitivities and interest.

The media workshop for journalists and broadcasters, organized by UNESCO in Mexico following the world Conference formulated a series of recommendations to media, professional communicators, governments and intergovernmental bodies and nongovernmental organizations for the more effective use of media and the increased participation of women as media professionals (Medium Term Plan, UNESCO, 1977).

The was followed by the Caribbean Women's feature syndicate setup under contract between UNESCO and the Christian Action for Development in the Caribbean.

In Asia, the Depth News women service was setup under contact with the Press Foundation of Asia. The network increased to African and Arab States. The Ultimate 
purpose was to help remove prejudices and stereotypes reflected in the mass media and thus the speed up women's full equality with men. Soon after a series of regional seminars were organized by the UNESCO in the field of women and media devoted to women and media decision - making. A number of this kind activities were launched at the headquarters in 1980. The fundamental aim of activities was to sensitize high level media managers to the implication for society of the neglect women, both as audience members and media personnel. The participant of the seminar stressed the need to overcome problems concerning women and the media (Medium Term Plan, UNESCO, 1977).

The first seminar on women and media decision making took place in Jamaica in 1981 for the Caribbean region organized by the Caribbean Institute of Mass Communication. Later that year, the second regional seminar for Asia- Pacific Institute for Broadcasting Development. A third seminar, for Latin America, was held in Mexico in March 1982 while a fourth took place in Fiji for the Pacific region at the end of 1982 organized by the Extension Services of the University of the South Pacific. The fifth was held in 1983 in Tunis for the Arab States, organized by the Union Nationale des Femmes de Tunisie. This was the first time the subject was discussed by participants, both men and women, of the Arab States under the auspices of an international organization. The sixth seminar was held in Warsaw, organized the International Organization of Journalists (IOJ) in October 1984. It marked the first time that participants from all over Europe- North and South, East and West including North America -discussed women and media on such a wide basis. The seventh and last in this series was held for the African region of the subSahara in February 1985, organized in Addis Ababa by the African Training and Research Center for Women, Economic Commission for Africa (Agarwal, Bindod, 1984).

It was stressed that in electronic media production women would be involved as equal partner of society. This was reiterated in specific recommendations concerning women in the media and formulated in various meeting at experts on cooperation among Regional Communication Training Institutes, UNESCO, Paris in 1990. Later, UNESCO held a series of courses in the leading regional communication training institute through the world. UNESCO also financed national and inter-regional seminars in Puerto Rico, Panama, the Dominican Republic, Malaysia and USA, in which, particularly women of the developing countries participated. UNESCO has published global reports and a books on the image and role of women in media in 1990 (Agarwal, Bindod, 1984).

On the research side, UNESCO has published two global reports and a book on the image and role of women in the media: "The Portrayal and Participation of Women in the Media" by Margaret Gallagher of the Institute of Educational Technology, the Open University, United Kingdom; 'Mass Media: the image, Role and Social Conditions of 
Women' by Mieke Ceulemans and Guido Fauconnier of the Catholic University of Leuven and the book 'Unequal Opportunities: the Case of Women and Media' by Margaret Gallagher. Other studies have been published from Canada, Jamica, Japan and Senegal on the impact of cultural (media) industries on the socio-cultural behaviour of women which were discussed in Helsinki at an expert meeting organized by UNESCO and the Finnish National Commission (1979). In addition, a publication entitled 'Women in the Media' which included an enquiry on participation of women in radio, television and film in four countries; Australia, Canada, United Kingdom and the United States was issued by UNESCO in 1980.

Through UNESCO, particular activities related to women and communication have benefitted women's status. In the course of the development of its programmes for women and media, various kinds of interaction and priority-setting have taken place. The programmes have responded, with varying degrees of sensitivity, on the perception of women's issues in the world outside, both perceptions based on research and evaluation and gradual changes in national and regional media structures. In this connection the 1980 year was significant, when activities in women's fields were widely diffused across the sectors. An International Committee for coordination of activities concerning women was established. This committee continued to work and has been strengthened by the appointments, in 1984, a coordination for activities relating to the status of women. The creation of such a post had been proposed of the 20th session of UNESCO's General Conference in 1978. The eventual appointment made at Director level meant that for the first time women's issues could be looked for consistently throughout all major programmes, including that for communication (Agarwal, Bindod, 1984).

From 1980 onward research was emphasised and a series of summaries and reference materials were prepared and published in Mass Media and the image and social conditions of women. These studies were based on an analysis of research and project developments around the world. The studies outlined women's issues, women's participation in communication industries, policy making and decision making, and their relative significance as compared with men.

Later, on a series of action oriented case studies of obstacles to the promotion of women into management were carried out in different regions of the world, including Asia region on this basis of these studies a set of communication. Strategies were made with a view to raising public awareness of the problem. UNESCO has a particular interest in women issues and commitment to follow up on those issues. The relationship between women and media must be set in the overall context of the existing communication structures at the national and international levels. The specific problem of women have to be set within this context, and ways to overcome these problems concerning the society as a whole. 
Communication is probably the most powerful form of support, since motivation is sine qua of all successful movements. Women empowered with knowledge and ideas constitute the strongest force for change through communication, television and film which are the most effective, but many have limited outreach, except radio probably reaches the largest women audience. Recorded cassettes has emerged as a tool in the dissemination of messages in female population. In most developing countries, newspapers reach only a small section of the literate population, but are read by all decision makers. Other print media have their audience and can constitute effective channels in the communication ideas, related material are produced. The support and involvement of leading women in popular issues like family planning, literacy, adult education, cooperatives, women youth, girl guides and class and social organization etc are almost always invaluable. Uncontroversial religious and social organizations can constitute strategic partners. All organization are potential allies. Favourable international public opinion, international interest and material and financial support are rewarding symbols of the recognition of women role in various movements.

Studies of women's image in the media, including advertising and school text books have been conducted in many parts of the world confirming that women continue to be portrayed in a traditionally stereotyped.

The media in Turkey tend to portray women as 'mother, wife, sex symbol', whereas in Senegal they show her as 'mother, wife, agent for development'. In the Republic of Korea, when the media depict a working woman, she is 'seldom happy'. Sudanese media find it 'incumbent upon them to portray women in an optimal image consistent with the Shari's (Islamic law)". Denmark complains of 'sex stereotypes', the Ivory Coast and the Netherlands' of advertising's exploitation of women's image as symbolizing 'charm, beauty, frivolity, fragility' when they are not shown as 'mothers and housekeepers'. "Petty Bourgeois" images of women survive in Yugoslavia. A study sent in by Costa Rica analyses advertising's concentration on domestic activities and personal appearance, and documents the stereotypes used to project an illusion of social mobility to the deprived masses. In school textbooks, concludes the study, 'man is the leader, he who has a place in history' (UNESCO, 1985).

The world conference on the UN decade for Women, Nairobi, 1985 has distributed a questionnaire to United Nations Member states by the Branch for the Advancement of Women (UN Center for Social Development and Humanitarian Affairs as a part of data collection for the review and appraisal of achievements of the UN decade for women, contained a section on communication and the media. To answer the question 'Has there been any change since 1975 in the media images" out of 95 governments 44 governments answered yes, while 28 answered no (UNESCO, 1985). 
However, it is clear that a number of the 'yes' replies actually refer to perceived changes in women's role in society, rather than to changes in media images of that role. Taking only those countries whole replies related unequivocally to changes in media portrayal, the yes-no balance is about 50-50. The type of progress reported generally involved increased portrayal of women in professional situations (Ecuador, Jordan, Madagascar, United States, Zimbabwe), greater respect for women (Switzerland), greater equality of treatment (Finland), France remarks that the change process has been helped by the establishment - by the Ministries of Women's Rights and of Education - of some 50 committees to monitor the content of school text books. Countries which have undergone revolution, or coups, usually gave accounts of a complete transformation of media content concerning women dating from the change in regime. In the case of the Soviet Republics, this transformation is said to date back to 1917, for Poland to 1945, and for Burundi to the establishment of "the Second Republic" revolution, the image of women projected by the broadcast media in Cuba has undergone a total change. The image now presented is that of the worker -students, militants, professionals - an involved participant in all branches of Cuban daily activity". In (Quebec, Canada) a more complex situation exists: 'An effort has been made in advertising, but more needs to be done. Sexism has taken on more subtle forms. Problems remain in the treatment of so-called women's news. Visual and written pornography have become a source of grave concern, with themes of violence and humiliation aimed against women on the increase'. Finally, the immense difficulty of making an objective response to this question is underlined by the New Zealand reply: 'Women are probably being portrayed in a wider variety of roles and occupations (in addition to their traditional 'supportive' role) but there is no detailed evidence available to support this statement' (UNESCO, 1985).

Only 23 responding governments (less than a quarter) reported the existence of analyses of the roles and functions of the women's press and broadcast programmes for women in their countries. A small number of these governments provided summaries of the findings. The Mass Media and Infant Health Project in the Gambia showed that radio programmes benefitted women especially in the area of maternal and child health. An Indonesian study showed that reading and programmes for women have played an important role, stimulating greater activities and productivity, especially among women was that the women's press concentrates on subjects linked with modern women's basic requirements, whether such subjects are related to legal, social, family or economic aspects. In Madagascar, it was found that 'women act as information relays and can translate advice given on the radio into operation terms: Broadcasting the experience of other women stimulates emulation'. An audience research report showed that the Swedish feminist radio station, Radio Ellen, reaches I percent of the population, comprising equal numbers of women and men. The United States reported a study of press coverage which found that feminist publications 'reach more women, and are 
stronger initiators of action by women on women's issues, that the mainstream press' (UNESCO, 1985).

\section{Conclusion}

A global review of the research into the portrayal and participation of women in the media shows that portrayal of women is narrow, at worst, it is unrealistic and damaging. Although advertising has generally been found most reactionary, women's portrayal in news and entertainment has been little better. Certain cultural differences have been noted and media portrayals have been found to be most positive in these countries with a firm commitment to the social and economic integration of women. With few exception, however it has been shown that media present women as a subordinate sex. The present trend indicate the beginning of changes which, although slight a and media are not inescapably looked into a particular mode of presentation. In order to allow women to participate in development, media organizations should further promote their involvement in all programs related to nation-building. It is often the practice at present to limit women's involvement to program's relating only to women. Programmes should be produced for women's participation particularly aimed at attitudinal changes. It would be appropriate if research should be encouraged in order to discover forms of expression in alternative communication by women in different social and cultural backgrounds. Continuing research should be carried out on women's functions and role in the media both as creators and consumers. It is also important to study the content of media output in terms of norms and values relating to the image of women, and to place emphasis on action-oriented research.

\section{References}

Agrawal, Binod C; Communication Research Related to Women and Children in paper presented in ICCTR-UNICEF 1984.

"Information and Communication as Development Resources for the Advancement of Women", world Conference of the UN Decade for Women, July 1980, A / conf. 24/27, Para 20.

Mac Bride, Sean etal. Many Voices, One World, London, New York, Paris, UNESCO, 1980.

Medium Term Plan (1977-1982) 19 c/4 approved, Paris, UNESCO, 1977.

Montagu, Ashley and Matson, Floyd (1979) The Human Connection, New York: McGraw Hill, P-VII. 
UNESCO (1985) Communication in the Service of Women: A Report on Action and Research Progress, 1980-1985.

World Conference of the UN Decade for Women, (1980) Programme of Action for the Second Half of the UN Decade for Women: Equality, Development and Peace. Copenhagen, July 1980, A / Conf. 94/34; Para 30.

Dr. Abida Perveen is Assistant Professor in the Sheikh Zayed Islamic Research Centre, University of Karachi. 